\title{
Valuing IS/IT Resources as an Antecedent of Ab- sorptive Capacity: An RBV Perspective
}

\author{
Hernán Joglar and Julián Chaparro \\ Escuela Técnica Superior de Ingenieros de Telecomunicación, \\ Universidad Politécnica de Madrid (UPM), Madrid, Spain
}

\section{hjoglar@gio.etsit.upm.es chaparro@gio.etsit.upm.es}

\begin{abstract}
Knowledge recognition as an organizational asset of strategic importance has generated growing interest on absorptive capacity. Surprisingly enough, research on the factors that originate this capacity has been rather scarce. Thus, existing knowledge on the matter suffers relevant omissions. One significant factor that has been excluded from the identified set of antecedents is the collection of resources and capabilities that derive from information systems and information technology (IS/IT). Therefore, this article is aimed at developing the arguments that justify considering IS/IT resources as an antecedent of absorptive capacity, and also at identifying the main relationships among these resources and the most relevant antecedents previously identified. This research concludes that IS/IT resources not only are an important antecedent of absorptive capacity, but also play a moderating role over the effects of many other antecedents.
\end{abstract}

Keywords: Knowledge management, absorptive capacity, absorptive capacity antecedents, IS/IT resources and capabilities.

\section{Introduction}

Strategic relevance of knowledge has been widely recognized for about two decades (Grant, 1996b; Nonaka, 1991; Sambamurthy, Bharadwaj, \& Grover, 2003). The increased interest on knowledge has focused organizations on skills that enable knowledge creation, diffusion and exploitation. One of these skills is absorptive capacity, a "dynamic capability" that allows organizational knowledge creation and utilization (Zahra \& George, 2002). It enables organizations to recognize the value of new external knowledge, assimilate it and apply it to commercial ends (Cohen \& Levinthal, 1990). Considering absorptive capacity as a "dynamic capability" implies that it is an essentially strategic capability (Teece, Pisano, \& Shuen, 1997), and that it is conceived to influence organizational changes and, therefore, to define the firm's future organizational evolution (Zahra \& George, 2002).

According to Lane, Koka, and Pathak (2002), one of the most salient shortcomings of absorptive

Material published as part of this publication, either on-line or in print, is copyrighted by the Informing Science Institute. Permission to make digital or paper copy of part or all of these works for personal or classroom use is granted without fee provided that the copies are not made or distributed for profit or commercial advantage AND that copies 1) bear this notice in full and 2) give the full citation on the first page. It is permissible to abstract these works so long as credit is given. To copy in all other cases or to republish or to post on a server or to redistribute to lists requires specific permission and payment of a fee. Contact Publisher@InformingScience.org to request redistribution permission. capacity literature is the little attention paid to the actual processes underlying its formation, i.e. its antecedents. Additionally, it is interesting to observe that the antecedents identified in literature are distinctly - and in part wrongfullyskewed towards those that enable tacit knowledge creation, whereas explicit knowledge generation is relegated or simply omitted. This tendency, which 
ignores the symbiotic relations existing among both knowledge types (Nonaka, 1994), has led to exclude from the identified antecedents the set of resources and capabilities associated to IS/IT. These are one of the most widely expanded and utilized sets of technologies in today's business world. Thus, an influential avenue to organizational strategic success might have been ignored so far.

Consequently, the objective of this article is to develop the arguments that justify considering IS/IT resources as an antecedent of absorptive capacity and to highlight the links between these resources and the most important antecedents already recognized in literature.

This paper contributes to the knowledge of absorptive capacity antecedents by emphasizing the need to refine the focus of search for relevant antecedents. An effective set of antecedents should target to joint, efficient, and balanced development of tacit and explicit knowledge. Besides, we identify an overlooked group of antecedents and underline the reach and value of their contribution to absorptive capacity generation. We then incorporate this set of antecedents in an already accepted model depicting absorptive capacity formation and effects.

This paper is organized as follows: in the next paragraph we portray the strategic value of IS/IT resources. Then, we review the literature on absorptive capacity and its antecedents. Next, we analyze the effects of considering IS/IT resources as antecedents of absorptive capacity. Finally, we propose integrating IS/IT resources within the Model of Determinants of Absorptive Capacity.

\section{IS/IT Resources from an RBV Perspective}

During the mid 1980s and based on earlier organizational strategy theories, such as Nelson and Winter's work (1982), the resource-based approach to strategic analysis started to unfold. This perspective suggests analyzing organizational outcomes based on the possession, control or utilization of a specific set of resources (García \& Navas, 2004). The resource based view of the firm (RBV) states that enterprise resources and capabilities may be understood as a collection of elements, factors, assets, skills and attributes, possessed or controlled by firms, which enable them to formulate and implement a competitive strategy (Navas \& Guerras, 1998).

Within this context, many authors have referred to IS/IT resources as an important means to contribute to enterprise objective accomplishment. It has been argued that these resources may influence competitive positioning (Griffiths \& Finlay, 2004) and may provide access to competitive advantages (Hirshheim \& Sabherwal, 2001). Nevertheless, increased interest has focused more upon different ways of utilizing such resources than on resources themselves. This is due to the commodity character attributed to these resources as IT access has become more easily available. In fact, since IS/IT resources may be at the reach of most organizations nowadays, it becomes reasonable to argue that they are necessary but not sufficient to accomplish competitive advantages (Bharadwaj, 2000; Dehning \& Stratopoulos, 2003). These advantages, instead, are achieved by integrating these resources with other organizational elements, and through creative and innovative applications of such combinations for strategic ends.

As stated by Bharadwaj (2000), "IT resources" consist of the physical IT infrastructure; IT human resources (including IT technical and managerial skills) and IT based intangible resources (such as knowledge assets). Additionally, this author defines "IT capabilities" as the firm's ability to mobilize and deploy IT based resources in combination with other resources and capabilities.

Following the above observations and definitions of IS/IT resources and capabilities, and taking into account their fundamental purpose (i.e., to generate competitive advantage), we may naturally infer that one of the most significant applications of these resources is the formation of absorptive capacity. To back this argument, we have noted that the most important elements are not IS/IT resources; but the combination of these resources and the adequate skills to exploit them for 
strategic purposes. We have also pointed out, in the introductory section above, that absorptive capacity is a strategically essential ability, as it directly influences future organizational progress. Additionally, in the course of this paper we will demonstrate that information systems play a relevant role in its generation. Therefore, we argue that one application of IS/IT resources that provides direct contribution to competitive strategy implementation is their deployment for absorptive capacity generation.

Furthermore, researchers in the RBV area assert that resources and capabilities must exhibit some distinctive characteristics to be considered strategically valuable (Barney, 2002; Dierickx \& Cool, 1989; Grant, 1996a; Navas \& Guerras, 1998; Peteraf, 1993). These authors claim that resources should be scarce, relevant, long-lasting, hardly transferable, difficult to imitate and replace, complementary, appropriable, socially complex and slow to build up. Now, if we observed IS/IT resources as an antecedent of absorptive capacity, we would find several of these characteristics fulfilled. In fact, these antecedents constitute a unique combination of resources, made up of mutually complementary elements, which also have a significant social component. Such resource arrangement gives rise to the conditions required to increment organizational knowledge stock, which is a scarce resource, slow to build up, and difficult to transfer and imitate (Grant, 1991). Additionally, these antecedents allow discovery, assimilation and exploitation of new practices and knowledge, all of which are considered essential abilities for achieving sustainable competitive advantages (Grant, 1996b; Teece, et al., 1997).

\section{Absorptive Capacity}

Absorptive capacity was originally defined as the firm's ability to recognize the value of new external knowledge, assimilate it and apply it to commercial ends (Cohen \& Levinthal, 1990).

Based on this definition, many complementary conceptualizations have emerged; but the orientation of the original definition is still in force. Lane and Lubatkin (1998) introduced the concept of "relative absorptive capacity". They claimed that this capacity is developed in a dual relationship aimed at transferring knowledge from a "teacher" organization to a "student" organization. A few years later, Zahra and George (2002) approached this concept as a "dynamic capability" related to knowledge creation and utilization that enhances a company's ability to achieve competitive advantage that yields superior performance.

Cohen and Levinthal (1990) highlighted three main components or dimensions of absorptive capacity: identification, assimilation and exploitation of new external knowledge. These dimensions have been recognized by authors of subsequent absorptive capacity models (Lane \& Lubatkin, 1998; Van den Bosch, Volberda, \& de Boer, 1999). However, Zahra and George (2002) introduced a more complete structure with four dimensions, which essentially maintains the previously existing components and adds a new one, "transformation". They termed their four dimensions as follows: acquisition, assimilation, transformation and exploitation. These four components must build on each other to yield organizational absorptive capacity (Daghfous, 2004; Zahra \& George, 2002).

Acquisition: represents the ability of an organization to identify, recognize the value and acquire external knowledge, which is critical for its operations (Lane \& Lubatkin, 1998; Zahra \& George, 2002).

Assimilation: denotes the procedures, routines and methods that allow an organization to digest and understand the information acquired from external sources (Szulanski, 1996; Zahra \& George, 2002).

Transformation: is a firm's ability to develop routines that facilitate the combination of existing knowledge with newly acquired and assimilated knowledge (Zahra \& George, 2002). Transfor- 
mation can be achieved by adding or deleting knowledge, or interpreting existing knowledge in a different way (Daghfous, 2004).

Exploitation: represents the array of routines that allow a company to improve, expand and leverage existing capabilities or to create new ones by including acquired and transformed knowledge into its operations (Zahra \& George, 2002).

Zahra and George (2002) also suggested that absorptive capacity exists as two subsets consisting of potential and realized absorptive capacity. "Potential absorptive capacity" includes knowledge acquisition and assimilation skills, which enable an organization to value and comprehend external knowledge but do not guarantee its application. "Realized absorptive capacity", on the other hand, is composed of knowledge transformation and exploitation, which allow a firm to convert external knowledge into useful insights and to utilize it to accomplish its objectives. Potential and realized absorptive capacity have different but complementary roles, they coexist at all times and they both add up to form absorptive capacity as originally defined by Cohen \& Levinthal.

Regarding the fundamental characteristics of absorptive capacity, a first noteworthy feature is that absorptive capacity is path dependent, which means that it is a function of previous accumulation of related knowledge. Building up absorptive capacity in one period will allow its more efficient accumulation in the next one. Similarly, by having already developed some absorptive capacity in a particular area, a company is better prepared to accumulate what additional knowledge it needs in the following periods in order to leverage any external knowledge that may become available. Path dependency emphasizes the need to capture insights learned through experience and to retain them within organizational memory, which, in turn, highlights the value of applying IS/IT resources in absorptive capacity formation.

A second important feature of absorptive capacity is its relation with organizational communication structures. Cohen and Levinthal (1990) identify communications quality as a significant factor for absorptive capacity creation, either among internal units or at the interorganizational context. Subsequent investigations have kept on these lines. Some of them have conducted research on vertical and horizontal internal interfaces (Jansen, Van den Bosch, \& Volberda, 2005; Lenox \& King, 2004; Szulanski, 1996; Van den Bosch et al., 1999; Van den Bosch, Van Wijk, \& Volberda, 2003); some others have studied the relationships between multinational companies and its subsidiaries (Mahnke, Pedersen, \&Venzin, 2005; Minbaeva, Pedersen, Bjorkman, Fey, \& Park, 2003); still others have researched interactions among independent corporations (Lane \& Lubatkin, 1998; Malhotra, Gosain, \& El Sawi, 2005). This growing interest on communication patterns emphasizes the relationship between absorptive capacity and knowledge transfer process efficiency, where, again, IS/IT resources play an essential role.

Therefore, we can state that absorptive capacity is a dynamic capability aimed at creating and maintaining competitive advantages through knowledge incorporation and utilization. It depends on organizational ability to retain useful knowledge and to increase it by means of efficient internal and external communications.

From the above assertion we observe that current IS/IT functionalities are closely linked to the fundamental needs of absorptive capacity generation. A significant part of both knowledge retention and knowledge transfer are supported by IS/IT. Above all, these systems make available a crucial feature, speed. A high pace in moving knowledge around the cycle that enables absorptive capacity utilization is central for exploiting competitive advantages (Zander \& Kogut, 1995). Besides, it is often claimed that, within the rapidly changing environment of enterprises, organizational capability to build and leverage competitive advantages in a faster and cheaper fashion is vital for business success (Amit \& Schoemaker, 1993). 


\section{Absorptive Capacity Antecedents}

Absorptive capacity antecedents are a group of elements that must be gathered and combined to originate this capability. Conceptual developments of antecedents have been rather slow after its first introduction (Lane et al., 2002). Those antecedents initially identified by Cohen and Levinthal (1990) are still in effect, although they have been successively complemented thereafter.

\section{Antecedents at the Internal Organizational Context}

As noted above, Cohen and Levinthal (1990) stated that absorptive capacity is highly dependent on "previous knowledge". Hence, they identified a first group of antecedents. They also identified the elements within this group of antecedents: general knowledge of related domains; prior learning experience and shared language. Additionally, the same authors distinguished a second group of antecedents, which they call internal "organizational mechanisms". These include communication patterns, mechanisms and processes that allow new knowledge diffusion within the organization. This group of antecedents comprises internal and external organizational communication structure, and character and distribution of expertise and knowledge. As we state in the following paragraphs, descriptions of absorptive capacity antecedents made by different authors later on are all based on one or both of these two clusters of antecedents.

Van den Bosch et al. (1999) and Van den Bosch et al. (2003) keep building on Cohen and Levinthal's work. Their studies are mainly focused on organizational mechanisms, which they separate into two groups: "organizational forms" and "combinative capabilities". Regarding organizational forms, they claim that different structures (functional, divisional and matrix) have different effects on absorptive capacity. Combinative capabilities, on the other hand, refer to organizational internal mechanisms affecting absorptive capacity. The authors identify three types of combinative capabilities: systems capabilities, coordination capabilities, and socialization capabilities. Systems capabilities consist of the various aspects tending to formalize internal work. Coordination capabilities enhance absorption by facilitating relations within groups, among teams and between organizational units. Finally, socialization capabilities comprise much of the internal efforts made by firms to improve knowledge diffusion via common understanding development.

In their highly conceptual article, Zahra and George (2002) also contributed to antecedent identification. They expanded the scope of Cohen and Levinthal's (1990) definition of previous knowledge, by highlighting previous experience as a key antecedent, which tends to underscore the more tacit factors of previous knowledge. Besides, these researchers make an interesting contribution by identifying antecedents within the context that companies face. They recognized both external sources of knowledge and activation triggers as fundamental antecedents. The former refer to outside knowledge availability, whilst the latter are internal or external events that activate knowledge search and acquisition.

There also exists some research on organizational absorptive capacity in specific contexts. Lane, Salk, and Lyles (2001) studied learning among international joint venture (IJV) partners. They found that the most relevant antecedents are trust between participant organizations; IJV flexibility, learning processes and structures, and IJV strategy.

By year 2003 research specifically aimed at identifying and illustrating antecedents started to emerge. Minbaeva et al. (2003) and Mahnke et al. (2005) studied knowledge transfer among multinational subsidiaries; however they focused on antecedents at the individual instead of the organizational level as did earlier researchers. Minbaeva et al. (2003) identified employee's abilities (associated to previous knowledge) and employee's motivation as highly influential antecedents of absorptive capacity. Employee's abilities have been mentioned as relevant antecedents in a number of other investigations. Some specific factors that embody these abilities are motivational orientation, technological competencies, training, and employee's formal education, among oth- 
ers (Daghfous, 2004; Kumar \& Nti, 1998; Schmidt, 2005). Complementing these ideas, Mahnke et al. (2005) claim that knowledge management tools and practices implemented by higher management are the fundamental elements that enable absorptive capacity generation. In this vein, Lenox and King (2004) found that manager-provided internal information is a relevant antecedent.

The group of studies cited in the last two paragraphs exhibit two noteworthy characteristics. While they all propose antecedents that derive from the two fundamental factors influencing absorptive capacity generation (previous knowledge and organizational mechanism, which include communication patterns), the implementation of these antecedents may be supported by IS/IT in a great deal. First, employee's abilities may be acquired through learning support tools, such as simulation (Rivero, 2002), e-learning (Rosenberg, 2000) or by means of IS/IT resources specifically designed to ease knowledge transfer. Next, knowledge management (KM) tools are by nature part of an IS and KM practices are supported by these systems or embedded within them. Finally, manager-provided internal information should be communicated via an internal network or the Internet in order to accomplish timely, complete and cost-effective diffusion.

Table 1. Absorptive capacity antecedents, internal context.

\begin{tabular}{|c|c|c|}
\hline \multicolumn{2}{|c|}{ ANTECEDENTS } & \multirow{2}{*}{ SOURCE } \\
\hline MAIN & SECONDARY & \\
\hline \multirow[t]{3}{*}{ Previous Knowledge } & $\begin{array}{l}\text { General knowledge in re- } \\
\text { lated domains }\end{array}$ & $\begin{array}{l}\text { Cohen \& Levinthal (1990); Nonaka \& Takeuchi } \\
\text { (1995); Gupta \& Govindarajan (2000); Zahra \& } \\
\text { George (2002) }\end{array}$ \\
\hline & Problem solving skills & Cohen \& Levinthal (1990) \\
\hline & Learning experience & Cohen \& Levinthal (1990); Lane et al. (2001) \\
\hline \multirow[t]{2}{*}{$\begin{array}{l}\text { Organizational } \\
\text { mechanisms }\end{array}$} & Communication patterns & $\begin{array}{l}\text { Cohen \& Levinthal (1990); Nonaka \& Takeuchi } \\
\text { (1995) }\end{array}$ \\
\hline & Knowledge distribution & Cohen \& Levinthal (1990) \\
\hline \multicolumn{2}{|c|}{ External sources of knowledge } & $\begin{array}{l}\text { Zahra \& George (2002); Stock, Greis \& Fisher } \\
\text { (2001) }\end{array}$ \\
\hline \multicolumn{2}{|c|}{ Activation triggers (crises, failures) } & Zahra \& George (2002) \\
\hline \multicolumn{2}{|c|}{ Trust among partners } & Lane, Salk \& Lyles(2001) \\
\hline \multicolumn{2}{|l|}{ Partnership flexibility } & \\
\hline \multicolumn{2}{|l|}{ Partnership strategy } & \\
\hline \multicolumn{2}{|l|}{ KM tools and practices } & Mahnke et al. (2005); Lenox \& King (2004) \\
\hline \multicolumn{2}{|l|}{ Employee's abilities } & $\begin{array}{l}\text { Kumar \& Nti (1998), Minbaeva et al. (2003), } \\
\text { Schmidt (2005) }\end{array}$ \\
\hline \multicolumn{2}{|l|}{ Employee's motivation } & Minbaeva et al. (2003) \\
\hline \multirow{3}{*}{$\begin{array}{l}\text { Coordination capa- } \\
\text { bilities }\end{array}$} & Interfunctional interfaces & \multirow{3}{*}{$\begin{array}{l}\text { Van den Bosch et al. (1999), Van den Bosch et al. } \\
\text { (2003), Jansen et al. (2005) }\end{array}$} \\
\hline & $\begin{array}{l}\text { Decision making participa- } \\
\text { tion }\end{array}$ & \\
\hline & Job rotation & \\
\hline \multirow{2}{*}{$\begin{array}{l}\text { Socialization capa- } \\
\text { bilities }\end{array}$} & Connectedness & \multirow{2}{*}{$\begin{array}{l}\text { Van den Bosch et al. (1999), Van den Bosch et al. } \\
\text { (2003), Jansen et al. (2005); Cockburn \& Hender- } \\
\text { son (1998); Gupta \& Govindarajan (2000). }\end{array}$} \\
\hline & Socialization tactics & \\
\hline \multirow[t]{2}{*}{ Systems capabilities } & Formalization & \multirow{2}{*}{$\begin{array}{l}\text { Van den Bosch et al. (1999) Van den Bosch et al. } \\
\text { 2003); Jansen, et al. (2005); Daghfous (2004) }\end{array}$} \\
\hline & Routine & \\
\hline \multirow[t]{2}{*}{ R\&D activities } & Intensity & \multirow{2}{*}{$\begin{array}{l}\text { Cohen \& Levinthal (1990); Veugelers (1997); } \\
\text { Schmidt, (2005) }\end{array}$} \\
\hline & Continuity & \\
\hline \multirow{2}{*}{$\begin{array}{l}\text { Collaboration among } \\
\text { internal units }\end{array}$} & Formal Seminars & \multirow[t]{4}{*}{ Schmidt, (2005) } \\
\hline & Informal networks & \\
\hline Education & Employee's education level & \\
\hline \multicolumn{2}{|c|}{ Innovation and knowledge transfer encouragement } & \\
\hline
\end{tabular}


Table 1 shows a summary of the most relevant antecedents identified in literature for the internal organizational context. Some of them have been described above with some detail.

From our previous arguments, we conclude that, as studies have been specifically dedicated to absorptive capacity antecedents, major groups of antecedents have been subdivided into more unambiguous concepts. This evolution has assisted researchers in reducing the gap between theory and practice on this matter. As a result, the relationship between absorptive capacity formation and IS/IT resources and capabilities appears now more evident than ever.

\section{Antecedents at the Interorganizational Context}

Similar to what we observed at the firm's internal level, at the interorganizational context the antecedents of absorptive capacity exhibit early general descriptions leading to subsequent more specific propositions that are clearly linked to IS/IT resources and capabilities.

Focusing their attention on the interactions among two independent firms, Lane and Lubatkin (1998) proposed the first theoretical extension of absorptive capacity antecedents towards the interorganizational context. Using as foundation Cohen and Levinthal's ideas, these authors identify three relevant antecedents for absorptive capacity at this level. First, they argue that previous basic knowledge in both organizations should be similar, whereas specific knowledge should differ (knowledge base similarity). Second, they state that the interacting companies should have similar human resource compensation practices and similar organizational structure (knowledge treatment similarity). And third they assert that there should be similarity between the problems that both firms confront (knowledge utilization similarity).

Several years later, Malhotra et al. (2005) analyzed absorptive capacity antecedents within interactions among partner organizations operating in a common supply chain. They found two groups of antecedents: (a) partner interface-directed information systems and (b) integrative interorganizational process mechanisms. It is important to note that at the interorganizational context the value of IS for absorptive capacity generation is explicitly recognized. We believe that this might be due to the fact that most interactions between two organizations operating in a common system - such as a supply chain - take place within an information system.

In today's globalizing economy, specifically in the area of firm international expansion, Rhee (2004) argues that an important antecedent for building knowledge - and therefore absorptive capacity - about potential host countries is Internet usage and Internet infrastructure availability. Knowledge regarding tariff barriers, investment regulations, labor laws and so forth could be acquired and assimilated through the Internet. Here, again, IS are paramount for absorption.

The review of absorptive capacity antecedents in the last two sections allows us to argue that IS/IT resources play a relevant role in absorptive capacity generation. They not only contribute at substantiating every group of antecedents; but also do so at every organizational level where organizational knowledge may be accumulated.

\section{Visualizing IS/IT Resources as an Antecedent of Absorptive Capacity}

Based on business management and knowledge transfer literature, in this section we portray how important it is to recognize IS/IT resources as an antecedent of absorptive capacity. From our literature review above, we infer that absorptive capacity originates at successful interchange of knowledge between two entities, followed by efficient retention of the acquired insights in such a way that they can be utilized later on. While the first of these two conditions is based on efficient communications, the second is supported by knowledge preservation in an easily understood format that facilitates future exploitation. This general perspective leads us to believe that the central 
element towards envisioning IS/IT resources as an antecedent of absorptive capacity is the contrast between explicit and tacit knowledge. This distinction makes the difference between articulable (explicit) knowledge, which is prone to be managed through IS/IT, and non-articulable (tacit) knowledge, which has to be transmitted through personal contact or acquired via practical experience (Nonaka, 1994). Such dichotomy among the two types of knowledge and their corresponding different treatments are also reflected in literature (e.g. Grant, 1996a). Many times the interest is centered on tacit knowledge as these insights are more difficult to transfer, whereas explicit knowledge is overlooked since its treatment is perceived as fairly simple. This perspective is somehow misleading, and we view it as being an important element that hampers the necessary recognition of IS/IT resources as a lever to generate absorptive capacity.

First of all, from a knowledge creation perspective, Polanyi (1962) states that the process of acquiring knowledge - the "knowing" process - includes two components: "knowing by attending", which is a focal knowing, and "knowing by relying on", which is a subsidiary knowing. According to his arguments, we acquire knowledge by concentrating on a limited number of primary factors (focal knowing), while relying on our previous knowledge about other multiple and more subtle related aspects (subsidiary knowing). The latter knowledge can be said to be "tacit" as we cannot tell what the particulars about it are, and on the awareness of which we rely in order to attend to the entity comprising them (Polanyi, 1962). Hence, tacit knowledge acts as a background that allows the understanding of the element on which the attention is focused (explicit component). From these arguments we infer that both kinds of knowledge are necessary to learn, since the focal (or explicit) component stimulates consciousness, which in turn, activates unconscious usage of the subsidiary component. Therefore, learning takes place through a combination of tacit and explicit knowledge, which renders them both complementary and inseparable.

Nonaka's theory of organizational knowledge creation also regards both tacit and explicit knowledge as equally valuable (1994). They claim that it is in the transformation among these two kinds of knowledge where new insights are generated. They also point out that the transformation type they call "externalization" is a "quintessential" knowledge-creation process, as it is in this process where new explicit concepts are conceived from tacit knowledge (Nonaka \& Takeuchi, 1995). These ideas have been subsequently supported in KM literature (e.g. Zack, 1999).

From a managerial viewpoint, Nelson and Winter (1982) highlight the relevance of explicit knowledge as well. They argue that whether a particular bit of knowledge is articulable in nature or necessarily tacit is not the relevant issue. Rather, the point is whether the costs of articulation are sufficiently high so that the knowledge in fact has to remain tacit. In this respect, Hedlund (1994) highlights that the current fascination with tacit knowledge must not cloud the fact that organizations to a large extent are "articulation machines", built around codified practices and deriving part of their competitive advantages from smart, unique articulation.

Therefore, by refusing to codify knowledge, and then manage it through an IS, organizations are, on the one hand, hindering new knowledge development, which limits previous knowledge stock. And on the other hand, they are ignoring an important source of competitive advantage.

Observing the same topic from an economic standpoint Petersen, Pedersen and Sharma (2003), argue that knowledge codification changes some fundamental aspects of the economics of knowledge generation and distribution. The codification process entails high initial, fixed costs but allows firms to carry out knowledge distribution and transfer at very low marginal costs (Petersen et al., 2003). Consequently, by relegating the effort to codify knowledge and utilize IS/IT resources, firms might be neglecting the exploitation of significant economies in knowledge usage.

If we now analyze the current state of development of IS/IT resources and capabilities, it is not reasonable to think they can radically change the relations among both knowledge types descried above. Obviously, IT advances enhance decision-maker's opportunities for storing, retrieving and 
transmitting objective and already codified knowledge, whereas the tacit nature of the crucial experiential knowledge makes it less amenable to computerisation processes (Petersen et al., 2003). Even so, we must be prudent about this last statement, since the tacit condition of a great portion of knowledge is subject to change, and IS/IT resources may facilitate this transformation or bring down its costs. As an illustration of the potential support provided by IS/IT resources to tacit knowledge capture, we may cite "KnowledgeMail", a tool offered by the American company Tacit Knowledge Systems Corp. (Johne, 2001). This software supports incoming and outgoing email communications of an organization. The tool picks up key words from emails and then builds employees' personalized profiles. Thereafter, each employee decides what part of his profile should be posted on the organizational network for his expertise recognition. KnowledgeMail's main purpose is to find out who knows what within the organization. Later examples may be found in the spearhead technological areas of expert systems and artificial intelligence.

Once the cognitive, managerial, and economic decisiveness of explicit knowledge is recognized, the value of IS/IT for absorptive capacity formation becomes evident. The identification of explicit valuable external knowledge becomes straightforward, and its comprehension is considerably facilitated, which enables "Potential absorptive capacity" generation. Moreover, newly acquired explicit knowledge should evoke existing tacit knowledge enabling knowledge combination and integration with existing insights. This should activate new knowledge assimilation and utilization, which facilitates "Realized absorptive capacity" formation.

The cycle developed to generate absorptive capacity comprises every effort made to identify a body of external useful knowledge; to incorporate it into the organization (successful transfer); to utilize it for commercial ends (internal diffusion, integration and exploitation); and finally, to preserve it in usable conditions (retention as "previous knowledge"). Each time this cycle is executed; new insights increment organizational knowledge stock, thereby increasing its "ability to recognize the value of new external knowledge, assimilate it and apply it to commercial ends", which, in turn, enhances its capacity to absorb more complex and advanced new knowledge.

In light of the arguments presented and considering the characteristics of the cycle described above, we argue that it is impossible to generate absorptive capacity at the speed required at current business environment without exploiting IS/IT. These resources, combined with other antecedents, should allow iteration around absorptive capacity formation cycle to generate a balanced mixture of tacit and explicit knowledge, which leads to the desired competitive advantages. Consequently, information systems are actually an important antecedent of absorptive capacity.

\section{Enhancement Proposition of the Model of Determinants of Absorptive Capacity and Expectation Formation}

In this section we propose the enhancement of a framework introduced by Van den Bosch et al. (1999) that comprises absorptive capacity antecedents and outcomes. This framework, shown in Figure 1, is called Model of Determinants of Absorptive Capacity and Expectation Formation. Our proposition integrates into this framework the effects of IS/IT resources and capabilities on absorptive capacity formation. We have selected this model since it is one of the few in literature that clearly distinguishes the factors affecting absorptive capacity formation.

The model includes both of the fundamental factors identified by Cohen and Levinthal (1990): level of previous related knowledge and a group of distinctively organizational aspects. The latter aspects are clustered into two categories: organizational forms and combinative capabilities. Both of them have been described above in our section devoted to absorptive capacity antecedents.

The framework also describes two types of organizational outcomes: "expectation formation" and "exploitation/exploration paths". The effect of absorptive capacity on "expectation formation" 
was introduced by Cohen and Levinthal (1990). It consists of the ability to foresee economic potential and future applications of external knowledge. On the other hand, "exploitation/exploration path" implies that, as organizations develop absorptive capacity in one specific area, they tend to "explore", and therefore to "exploit", knowledge in the same area, since they are able to value available knowledge and to apply it to commercial ends.

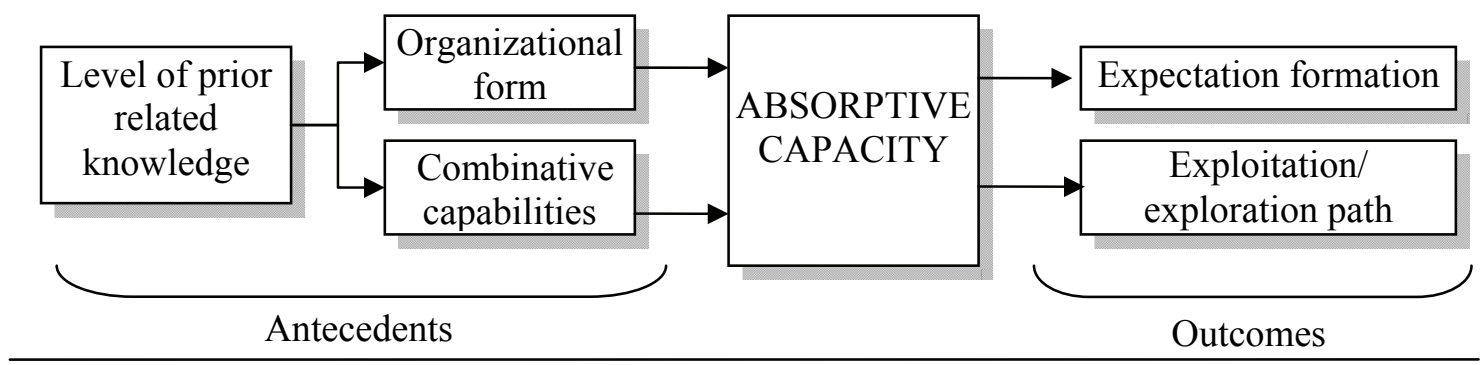

Source: Van den Bosch, Volberda, \& de Boer (1999)

Figure 1. Model of determinants of absorptive capacity and expectation formation.

In the following paragraphs we illustrate the relationships between the antecedents originally included in the model and IS/IT resources, which support the way these resources have been included in the proposed modification.

Prior related knowledge is composed of tacit and explicit knowledge that, as we have already pointed out, must amalgamate to become a usable whole. Because explicit knowledge is essential for eliciting the usage of the tacit component, it becomes crucial to enable recollection or reconstruction of existing knowledge. Additionally, IS/IT resources provide explicit knowledge with storage means; high information processing speed; and instantaneous global diffusion capability. Consequently, the effects of previous knowledge on absorptive capacity formation are moderated by IS/IT, since prompt availability of such knowledge is highly dependent on these systems.

As we have pointed out before, organizational forms are related to organizational structure. The model suggests that, ceteris paribus, different organizational forms enable or restrict absorptive capacity. To back their framework, the authors researched the effects of three different types of organizational forms: functional, divisional and matrix. They found that, among all three forms investigated, the matrix structure is the one that yields best conditions for absorptive capacity formation, whereas the effects of the division form are highly dependent on the context, and the functional structure generates a rather negative influence on absorptive capacity creation. What happens here is that different structures allow for different patterns of communication, which in turn, foster or hamper knowledge absorption. However communication patterns are drastically affected by IS/IT resources. Tools such as people finder systems, collaborative applications and conversational technologies, combined with the pervasive use of networks, offer a whole new set of possibilities to communicate globally, and either in real time or extemporally. Therefore, since organizational forms affect absorptive capacity formation through communication patterns, and these are profoundly moderated by IS/IT resources, then the effects of organizational structures are also moderated by IS/IT.

As we have briefly commented in previous sections, combinative capabilities include three kinds of lower level capabilities: systems capabilities, coordination capabilities and socialization capabilities. Systems capabilities are attained though firm official documents that regulate its internal functioning (manuals, procedure descriptions, technical documents, among others), which integrate explicit knowledge. The primary virtue of these capabilities is that they allow behavior programming in advance, and thus eliminate the need for further coordination. They provide a memory for handling routine situations (Van den Bosch et al. 1999). Because of their nature, these 
capabilities are usually attained through IS utilization. Document databases, corporate memory tools, portals and search engines are usually utilized to implement these capabilities. Systems capabilities without IS/IT would be highly inefficient and inconvenient. Accordingly, we argue that systems capabilities are moderated by information systems, which provide them ease of access, and almost unlimited storage space.

Coordination capabilities, in turn, enable absorptive capacity generation by facilitating timely information interchange among employees, departments and internal units. IS functionalities that support agile information flow become critical when attempting to develop this capability. This kind of interactions is considerably simplified by IS: contacts may be delocalized; real time communication may be avoided or utilized as needed, and significant amount of written, audible and visual material may be exchanged. Besides, all official information may be interchanged at high speed and considerable reliability. It is extremely difficult to obtain coordination capabilities within entities that have geographically distributed locations without intensively leveraging IS/IT resources. Hence, we argue that the effects of coordination capabilities on knowledge absorption are moderated by IS/IT resources.

Regarding socialization capabilities, they refer to the ability of a firm to produce a shared ideology that offers members an attractive identity as well as collective interpretations of reality. They also touch individual's affective factors that influence knowledge seeking. These capabilities consist of cultural aspects mostly composed of tacit knowledge. Nevertheless, it is possible to capture part of this knowledge and incorporate it into an IS. That is the case of principle declarations, policies, incentive allocation criterions, symbols and other conceptual aspects that influence organizational behavior. Additionally, by highlighting various aspects that encourage organizational objective accomplishment, IS also assist in shaping organizational culture. In this regard, Schein (1988) states that organizational culture is created by leaders, whose most important function inherent to leadership may be creating and shaping firm's culture. Among IS solutions that support culture shaping we can mention those that: (a) develop organizational identity (corporate websites); (b) foster organizational values (corporate portals, electronic bulleting boards); (c) assist communications (intranets); (d) facilitate learning (e-learning, simulation); and (e) support collaboration and knowledge diffusion (knowledge management tools). Thus, socialization capabilities, like other combinative capabilities, are acquired and operate, to a certain extent, via IS/IT resources. Therefore, we can also ascertain that socialization capabilities are moderated by IS/IT.

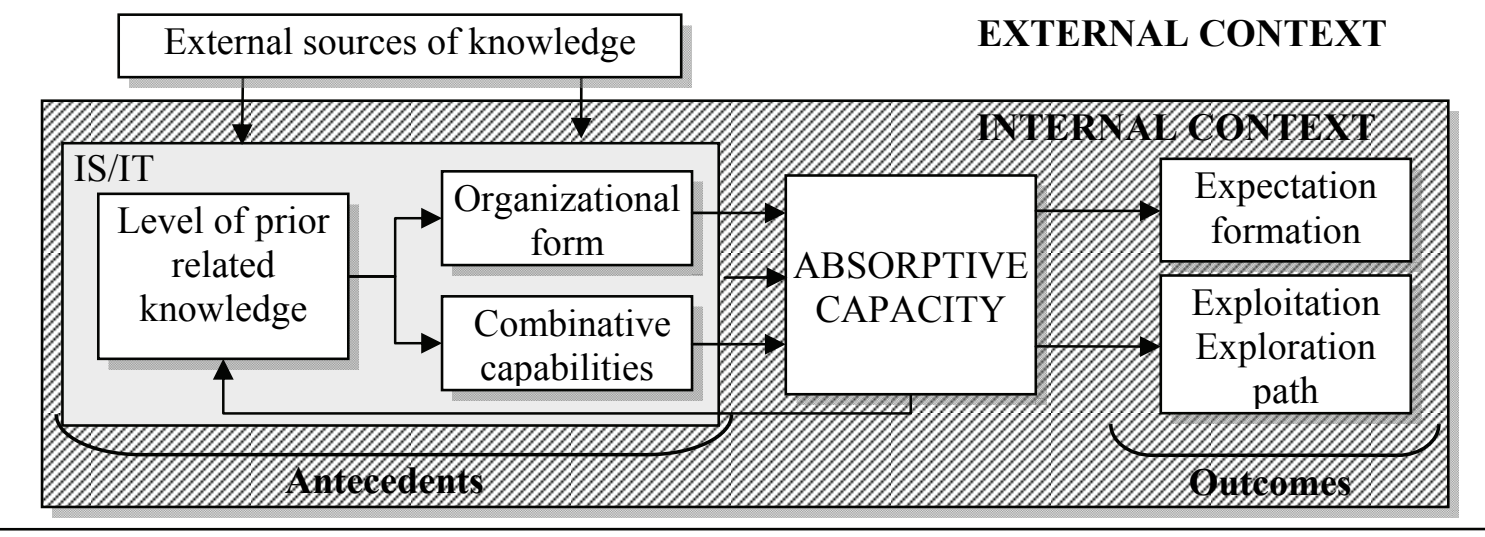

Source: Authors based on Van den Bosch, Volberda, \& de Boer (1999)

Figure 2. Modification of the model of determinants of absorptive capacity and expectation formation.

The arguments presented above have driven us to include IS/IT resources and capabilities in the model of Determinants of Absorptive Capacity with a twofold role: first, as an antecedent itself, 
and second, as a moderator of other antecedents, with which IS/IT reveal symbiotic relations (see Figure 2). The link between IS/IT and absorptive capacity stands for all the described functions of IS/IT that aid knowledge absorption; but are not included in the original model: technological competence development, training; formal education, common language diffusion, internal information provision, and information arrangement, processing and analysis. In summary, it symbolizes the vital role of a knowledge infrastructure on absorptive capacity formation.

An additional modifications of the model, as shown in Figure 2, comprise the insertion of external sources of knowledge, which include external IS, as an antecedent (originally proposed by Zahra and George, 2002). We consider, as well, the interactions among those external sources and both IS/IT in particular (identified by Malhotra, et al., 2005), which refer to explicit knowledge, and the organization in general, which refer to knowledge of a more tacit essence.

Moreover, we have included a feedback link from absorptive capacity to prior knowledge to depict the relation among these concepts. The transient status of absorptive capacity moderates external knowledge inflow. Once acquired, new knowledge is assimilated thus becoming potential absorptive capacity. Additionally, a fraction of the assimilated knowledge turns into realized absorptive capacity when it is transformed and exploited. The resulting knowledge at the end of this process becomes previous knowledge, and thus increments previous knowledge stock. Hence, the more absorptive capacity the more intense the incremental flow of incoming knowledge will be. Therefore, absorptive capacity works as a valve that regulates incremental prior knowledge flows.

Our model enhancement entails several theoretical and practical implications. First, our proposition improves the understanding of the complementarity and inseparability of tacit and explicit knowledge; both of these relations are often ignored in previous research. Second, this modification highlights the fact that companies are increasingly becoming dependent on business partners, and their connectedness status is essential to leverage external sources of knowledge. By combining internal and external knowledge, companies should be able to develop competitive advantages that are required to flourish in the constantly changing environment they currently face. Third, this model provides additional understanding of the necessary cooperative relationships that must exist among IS/IT and several strategically relevant organizational factors (knowledge, coordination, socialization, and formalization). The strength and alignment provided by these relations should enable enhanced utilization of technology for accomplishing corporate efficiency. And finally, our model provides a new set of criterions for structuring corporate IS functional requirements. These requirements should encompass, for instance, tacit knowledge capture functionalities and increased communication and coordination capabilities. In a more general sense, these prerequisites should be analyzed through the absorptive capacity lens in order to accomplish a new avenue to strategic advantages. Most important, such demands should be echoed in organizational IS exploitation practices.

\section{Conclusions}

This article has characterized IS/IT resources and capabilities from an RBV perspective, which drives to infer that strategic organizational capabilities may be derived from the utilization of these resources for absorptive capacity generation.

We have reviewed the literature that has conceptually developed the absorptive capacity construct. We have established that this capability derives from two groups of antecedents, previous related knowledge and organizational mechanisms, which includes knowledge diffusion and communication mechanisms. Both of these groups of antecedents base their effectiveness, at lest partially, on efficient utilization of IS/IT resources and capabilities. We have also reviewed the literature exclusively related to absorptive capacity antecedents. From these research articles we highlight that, as authors have focused specifically on absorptive capacity determinants, the major 
groups of antecedents identified in earlier research have been divided into more specific aspects that reveal direct or indirect dependency on IS/IT resources.

In addition, we have explained the effects of applying IS/IT resources as antecedents of absorptive capacity, while identifying common bias generated when treatment of explicit and tacit knowledge is unbalanced. Hence, we have established that explicit knowledge should become an aspiration, as it is essential for knowledge utilization. This, in turn, stresses the benefits of using IS/IT, given the advanced functionalities these technologies offer to manage explicit knowledge.

Leveraging the ideas above, we propose an enhancement of one of the existing models in literature that describes absorptive capacity generation. Our proposal includes two effects of IS/IT: a direct influence on absorptive capacity formation and a moderating role that acts on the influences of other antecedents. We finally discuss the theoretical and practical implications of our proposition.

Finally, we believe that our model enhancement opens several important directions for future theoretical development. First, this research has focused on the organizational level and its extensions to the internal unit and the interorganizational levels. In order to complete absorptive capacity formation landscape, it would also be interesting to investigate the effects of IS/IT on absorptive capacity at the individual level and at the industry level. Second, in this research we have described the impact of IS/IT as a whole; nevertheless interesting insights might be obtained if research was centered on the usage of particular IS, such as the Internet or interorganizational IS.

\section{References}

Amit, R. \& Schoemaker, P. (1993). Strategic assets and organizational rent. Strategic Management Journal, 14 (1), 33-46.

Barney, J. (2002). Gaining and sustaining competitive advantage $\left(2^{\text {nd }}\right.$ ed). New Jersey, NJ: Prentice Hall.

Bharadwaj, A. (2000). A resource-based perspective on information technology capability and firm performance: An empirical investigation. MIS Quarterly, 24 (1), 169-196.

Cockburn, I. \& Henderson, R. (1998). Absorptive capacity, coauthoring behavior and the organization of research in drug discovery. Journal of Industrial Economics, 46 (2), 157-182.

Cohen W. \& Levinthal, D. (1990). Absorptive capacity: A new perspective on learning and innovation. Administrative Science Quarterly, 35 (1), 185-203.

Daghfous, A. (2004). Absorptive capacity and the implementation of knowledge-intensive best practices Advanced Management Journal, 69 (2), 21-27.

Dehning, B. \& Stratopoulos, T. (2003). Determinants of sustainable competitive advantage due to IT enabled strategy. The Journal of Strategic Information Systems, 12 (3), 7-28.

Dierickx, I. \& Cool, K. (1989). Asset stock accumulation and sustainability of competitive advantage. Management Science, 35 (12), 1504-1514.

García, F. \& Navas, J. (2004). El fenómeno tecnológico y su estudio en el pensamiento estratégico. Ma$d r i+d$ 24. Retrieved May 30, 2006, from http://www.madrimasd.org/revista/revista23/aula/aula1.asp

Grant, R. (1991). The resource-based theory of competitive advantage: Implications for strategy formulation. California Management Review, 33 (3), 114-135.

Grant, R. (1996a). Prospering in dynamically-competitive environments: Organizational capabilities as knowledge integration. Organization Science, 7 (4), 375-387.

Grant, R. (1996b). Dirección estratégica. Conceptos, técnicas y aplicaciones. Madrid: Civitas.

Griffiths, G. \& Finlay, M. (2004). IS-enabled sustainable competitive advantage in financial services, retailing and manufacturing. Journal of Strategic Information Systems, 13 (1), $29-59$. 
Gupta, A. \& Govindarajan, V. (2000). Knowledge flows within multinational corporations. Strategic Management Journal, 21 (4), 473-496.

Hedlund, G. (1994). A model of knowledge management and the N-form corporation. Strategic Management Journal, 15, 73-90.

Hirschheim, R. \& Sabherwal, R. (2001). Detours in the path toward strategic information systems alignment. California Management Review, 44 (1), 87-108.

Jansen, J., Van den Bosch, F., \& Volberda, H. (2005). Managing potential and realized absorptive capacity: How do organizational antecedents matter? Erasmus Research Institute of Management. Retrieved February 14, 2006, from http://ideas.repec.org/p/dgr/eureri/30002188.html

Johne, M. (2001). What do you know? Management Magazine, March 2001, 21-25. Retrieved May 09, 2006, from http://www.linkpath.com/backIssue indexIssue.php?iIssueID=3000000312\& sIs$\underline{\text { sueAtAGlance }=\text { false } \& \text { iPageNumber }=21 \& \text { tempspeed }=\text { high } \& \text { flash }=0}$

Kumar, R. \& Nti, K. (1998). Differential learning and interaction in alliance dynamics: A process and outcomes discrepancy model. Organization Science, 9 (3), 356-367.

Lane, P. \& Lubatkin, M. (1998). Relative absorptive capacity and interorganizational learning. Strategic Management Journal, 19 (5), 461-477.

Lane, P., Salk, J., \& Lyles, M. (2001). Absorptive capacity: Learning and performance in international joint ventures. Strategic Management Journal, 2 (12), 1139-1161.

Lane, P., Koka, B., \& Pathak, S. (2002). A thematic analysis and critical assessment of absorptive capacity research. Academy of Management Proceedings. BPS. Retrieved July 24, 2006, from http://helios.univreims.fr/Labos/EUROP/Karama/7516527.pdf

Lenox, M. \& King, A. (2004). Prospects for developing absorptive capacity through internal information provision. Strategic Management Journal, 25 (4), 331-345.

Mahnke, V., Pedersen, T., \& Venzin, M. (2005).The impact of knowledge management on MNC subsidiary performance: The role of absorptive capacity. Management International Review, 45, 101-119.

Malhotra, A., Gosain, S., \& El Sawi, O. (2005). Absorptive capacity configurations in supply chains: Gearing for partner-enabled market knowledge creation. MIS Quarterly, 29 (1), 145-187.

Minbaeva, D., Pedersen, T., Bjorkman, I., Fey, K., \& Park, H. (2003). MNC knowledge transfer, subsidiary absorptive capacity, and HRM. Journal of International Business Studies, 34, 586-599.

Navas, J. \& Guerras L. (1998). La dirección estratégica de la empresa, teoría y aplicaciones ( $\left.{ }^{\text {nd }} \mathrm{ed}\right)$. Madrid: Civitas.

Nelson, R. \& Winter, S. (1982). An evolutionary theory of economic change. Cambridge: Belknap Press.

Nonaka, I. (1991). The knowledge-creating company. Harvard Business Review, November-December, 96104.

Nonaka, I. (1994). A dynamic theory of organizational knowledge creation. Organization Science, 5 (1), 14-37.

Nonaka, I. \& Takeuchi, H. (1995). The knowledge creating company: How Japanese companies create the dynamics of innovation. New York, NY: Oxford University Press.

Peteraf, M. (1993). The cornerstones of competitive advantage: A resource-based view. Strategic Management Journal, 14 (3), 179-171.

Petersen, B., Pedersen, T., \& Sharma, D. (2003). The role of knowledge in firms' internationalisation process. Wherefrom and whereto? In A. Blomstermo \& D. Sharma, Learning in the internationalisation process of firms. Northampton: E. Elgar Publishing.

Polanyi, M. (1962). Tacit knowing: Its bearing on some problems of philosophy. Reviews of Modern Physics, 34 (4), 601-616. 
Rivero, R. (2002). Claves y pautas para implantar la gestión del conocimiento, Bilbao: Ed. SOCINTEC, IBV.

Rosenberg, M. (2000). E-learning: Strategies for delivering knowledge in the digital age. New York, NY: McGraw-Hill.

Sambamurthy, V., Bharadwaj, A., \& Grover, V. (2003). Shaping agility through digital options: Reconceptualizing the role of information technology in contemporary firms. MIS Quarterly, 27 (2), 237-263.

Schein, E. (1988). La cultura empresarial y el liderazgo. Una visión dinámica. Barcelona: Plaza \& Janes editores.

Schmidt, T. (2005). What determines absorptive capacity? 39th Annual Meeting of the Canadian Economics Association, CEA. Retrieved May 14, 2006, from http://economics.ca/2005/papers/0149.pdf

Stock, G., Greis, N., \& Fisher, W. (2001). Absorptive capacity and new product development. The Journal of High Technology Management Research, 12, 77-91.

Szulanski, G. (1996). Exploring internal stickiness: Impediments to the transfer of best practice within the firm. Strategic Management Journal, 17, 27-43.

Teece, D., Pisano, G., \& Shuen, A. (1997). Dynamic capabilities and strategic management. Strategic Management Journal, 18 (7), 509-533.

Van den Bosch, F., Volberda, H., \& de Boer, M. (1999). Coevolution of firm absorptive capacity and knowledge environment: Organizational forms and combinative capabilities. Organization Science, 10 (5), 551-568.

Van den Bosch, F., Van Wijk, R., \& Volberda, H. (2003). Absorptive capacity: Antecedents, models and outcomes. Erasmus Research Institute of Management. Retrieved May 10, 2006, from https://ep.eur.nl/handle/1765/334

Veugelers, R. (1997). Internal R\&D expenditures and external technology sourcing. Research Policy, 26, 303-315.

Zack, M. (1999). Managing codified knowledge. MIT Sloan Management Review, 40 (4), 45-59.

Zahra, S. \& George, G. (2002). Absorptive capacity: A review, reconceptualization and extension. Academy of Management Review, 27 (2), 128-156.

Zander, U. \& Kogut, B. (1995). Knowledge and the speed of the transfer and imitation of organizational capabilities: An empirical test. Organization Science, 6 (1), 76-98.

\section{Biographies}

Hernán Joglar received a Bachelor of Science in Mechanical Engineering in 1999 and in Management Science in 1993. He also holds a Master of Science in Systems Engineering and Management from the Massachusetts Institute of Technology (MIT) and is currently a PhD student in Information Systems at the Universidad Politécnica de Madrid (UPM), Madrid, Spain. He has several years of experience in knowledge management in the public sector.

Julián Chaparro received the Telecommunication Engineer degree (Hons.) in 1990 and the PhD degree in Information Systems (summa cum laude) in 1995, both by the E.T.S. Ingenieros de Telecomunicación of the Universidad Politécnica de Madrid. Since 1990 he is a member of the Business Administration Department of the E.T.S. Ingenieros de Telecomunicación, becoming an associate professor in 1997. 